\title{
Cultura e trabalho: a integração do negro no Rio de Janeiro
}

\section{Culture and labor: integration of Black people in Rio de Janeiro}

\author{
Larissa Costa Murad*
}

\begin{abstract}
Resumo - Neste artigo objetivamos indicar a condição diferenciada do negro no Brasil após a instituição do trabalho livre. Além disso, destacamos a possibilidade de produção de determinada sociabilidade por segmentos negros no subúrbio carioca como resistência e consequência ao/do processo de homogeneização da cultura, resultante da universalização do trabalho alienado e do processo de expropriação continuada. Revisitamos principalmente os escritos de Florestan Fernandes para indicar a permanência de um padrão de relações raciais pautado na segregação difusa, em que é reservado aos negros um não lugar caracterizado principalmente pela vivência de piores condições. Observaremos também a ressignificação de formas culturais afro-brasileiras no processo de modernização tardia, indicador da integração do negro pela cultura no Rio de Janeiro, a qual ocorre no marco da consolidação da indústria cultural e da permanência desta forma específica de segregação.
\end{abstract}

Palavras-chave: trabalho; cultura; samba urbano; integração do negro.

\begin{abstract}
In this article, we indicate the condition of Black people in Brazil after the institution of free labor. In addition, we highlight the possibility of production of a certain sociability by Black segments in the Carioca suburbs as resistance and the result of the process of homogenization of culture. It arises from the universalization of alienated labor and the continued process of expropriation. To accomplish this, we revisit the writings of Florestan Fernandes to indicate the permanence of a pattern of race relations based on diffuse segregation, where a non-place characterized mainly by the experience of the worst conditions is reserved for Blacks. We observe also the resignification of Afro-Brazilian cultural forms in the process of late modernization, indicating the integration of Black people through culture in Rio de Janeiro, occurring in the frame of the consolidation of the cultural industry and the permanence of this specific form of segregation.
\end{abstract}

Keywords: labor; culture; urban samba; integration of Black people.

\footnotetext{
*Doutoranda em Serviço Social pela Escola de Serviço Social da Universidade Federal do Rio de Janeiro. Correspondência: Travessa Pepe, 98/301. Botafogo - Rio de Janeiro. CEP: 22290-020. Email: <larissamuradrj@hotmail.com>.
} 


\section{Introdução}

Neste artigo tecemos considerações sobre o lugar do negro durante o processo de modernização do Brasil, a partir da relação entre trabalho e produção de cultura no subúrbio do Rio de Janeiro. Indicamos em particular o movimento de expropriação e resistência pelo qual a cultura popular se constitui e constitui o subúrbio em suas expressões afro-brasileiras, sobretudo o samba urbano. Tal movimento envolve a resistência à segregação racial em sua forma difusa (FERNANDES, 2008) e, para explicitálo, revisitamos principalmente os escritos de Florestan Fernandes, além de termos traçado uma releitura dos escritos de Marx, particularmente dos Grundrisse, para expormos a generalização do trabalho alienado em sua relação com a instrumentalização da cultura. Quando esta ocorre, o negro é integrado por meio da produção da cultura, porém, como objeto e não na qualidade de sujeito produtor.

Notamos que a conformação do subúrbio carioca indica a forma de sociabilidade que possibilitou a construção do samba urbano no Rio como cultura popular; além disso, aponta as origens e particularidades da segregação étnica que acompanha a formação do Brasil em sua condição de país de capitalismo periférico que recrudesce em tempos de crise do capital. Está em questão a forma pela qual o país vivencia o processo de modernização e como este é sentido em um grande centro urbano como o Rio de Janeiro, por esse segmento étnico em particular. Interessa-nos também a maneira pela qual o segmento social em foco constrói sua subjetividade nesse movimento ambíguo de produção de cultura e reprodução dessa forma social.

Em condições de acumulação primitiva, a cultura popular só se produziu enquanto originalidade quando configurou resistência às formas mercantis de produção da vida social, tendo o impacto como recriação de formas de sociabilidade. Esta é uma noção fundamental para observar, inclusive, a produção de cultura no subúrbio do Rio de Janeiro em seus primórdios, no pós-abolição, momento no qual a sociabilidade negra pôde se recriar enquanto formas espontâneas de produção de cultura. No período de construção do subúrbio carioca, as formas de sociabilidade espontâneas dos negros recém-saídos da escravidão originam o samba urbano como consequência das idiossincrasias do próprio processo de modernização, bem como das resistências difusas à generalização do trabalho alienado, que surgem no decorrer do mesmo.

Nesse sentido, após a consolidação da indústria cultural e de entretenimento no país, as manifestações culturais afro-brasileiras são reapropriadas e ressignificadas enquanto mercadorias culturais, causando uma integração perversa do negro pela cultura; perversa visto que este se integra tornando-se objeto da cultura já fetichizada, como podemos observar no samba urbano contemporâneo. Esta integração se torna questionável tam- 
bém ao observarmos os indicadores sociais referentes à população negra brasileira ${ }^{1}$, os quais explicitam a permanência de formas de segregação difusa (FERNANDES, 2008), sentidas, por exemplo, no mercado de trabalho e no extermínio e encarceramento da juventude negra.

\section{A relação cultura e trabalho na conformação do território}

A produção de cultura popular no Brasil remonta a formas de resistência de determinados segmentos oprimidos perante o avanço das relações sociais mercantis. Cabe ressaltar que o termo cultura popular é entendido aqui a partir da noção desenvolvida por Raymond Williams (1979; 2007), segundo a qual as palavras possuem sentido histórico, ou seja, seu sentido se modifica conforme a mudança nas práticas sociais. Desse modo, podemos falar em cultura popular a partir das práticas que representaram resistência ao processo de desenvolvimento das relações mercantis no Brasil, no período anterior à generalização da cultura em sua forma sistêmica. Quando já amadurecidas as relações mercantis e consolidada a indústria cultural no Brasil, no período pós-década de 1970, o termo cultura popular é ressignificado, passando a denotar um nicho de mercado.

A civilização que nasce do processo colonial de acumulação primitiva se torna urbana pelo deslocamento contínuo de grandes contingentes populacionais, por meio da expropriação continuada e também como necessidade inerente ao desenvolvimento do urbano e à instituição do trabalho livre. Esse processo se inicia e se perpetua com o desenraizamento forçado de diversas etnias, o qual envolve a colonização de culturas diferentes e a imposição da raça como determinante, mesmo na ausência de um discurso explicitamente racista.

Segundo Cardoso (2006), a exploração social característica do capitalismo se substantiva no mercado das cidades. Nesse sentido, a construção de metrópoles é inerente ao processo de conformação do capitalismo. Para Abreu (2013, p. 16), "as áreas metropolitanas brasileiras são, na atualidade, uma das expressões espaciais mais acabadas da formação social brasileira", ou seja, no processo de construção das regiões metropolitanas se substantivam as contradições inerentes ao desenvolvimento desta forma social sistêmica. O autor destaca o lugar do Rio de Janeiro como modelo urbano, o qual reflete características da formação social como um todo:

O caso do Rio, então, parece ser ainda mais significativo, pois, além de ter sido aí que se localizou a capital do Brasil de 1763 a 1960, a cidade foi a mais populosa do país durante quase todo esse período,

${ }^{1}$ Ver: Rosemberg e Piza (1995/1996); Menezes (2013); Paixão (2014); Ipea (2014). 
só perdendo essa posição privilegiada para São Paulo na década de 1950. Devido a isso, o Rio de Janeiro foi, durante muito tempo, um modelo urbano para as demais cidades brasileiras. E esta função de servir de modelo e de refletir, por conseguinte, as características da formação social num determinado momento, parece ainda ser um monopólio seu. (ABREU, 2013, p. 16; p. 17).

O Rio de Janeiro experimenta o início de sua urbanização já no século XIX, com a vinda da família real portuguesa em 1808 e as consequentes mudanças na sociabilidade local. A vinda da família real implica em novas necessidades materiais, impondo maior nível de estratificação social ao Rio, cuja maioria da população até então era escrava. Combinando esse fator à independência política e ao boom do café, o Rio passa a atrair mais trabalhadores livres e capitais internacionais a partir principalmente de meados do século XIX. Até então a maioria de sua população era escrava. Rio de janeiro, São Paulo e Minas Gerais eram as três províncias com maior concentração de escravos.

Lopes (2008) destaca os fatores externos de atração de imigrantes para o Rio a partir do final do século XIX. O princípio da substituição do escravo por equipamentos agrícolas em algumas regiões do país, combinado aos efeitos da seca no Nordeste, provoca a venda de grandes contingentes de escravos para os grandes centros - especialmente Rio e São Paulo. Com a abolição da escravatura, a concentração populacional no Rio aumenta devido aos processos migratórios dos então libertos, desencadeado por diversos fatores.

Com a abolição da escravatura, entretanto, é que a capital do Império vai ter sua população, de fato, aumentada. Aos migrantes do Vale do Paraíba, que para o Rio de Janeiro continuam vindo desde a falência da lavoura cafeeira na região, aos veteranos da Guerra do Paraguai, aos flagelados da Grande Seca vêm juntar-se, agora, mais e mais negros, oriundos das mais diversas regiões do País, mas principalmente das províncias vizinhas. (LOPES, 2008, p. 39).

Ou seja, sendo o Rio de Janeiro a capital da República, seu processo de urbanização, até então incipiente, combinado às consequências das transformações sociais que ocorriam em todo o Brasil, atraía contingentes de imigrantes e recém-libertos. Em 1890, 34\% dos habitantes da capital eram "negros ou mestiços", dentre os quais grande parcela era oriunda de outras regiões do país (LOPES, 2008). A afluência dos imigrantes para o Rio era, obviamente, direcionada à área central.

O processo de urbanização ganha forma no século XX com a Reforma Pereira Passos (1903), a qual representou politicamente uma tentativa de adequar a estética local aos padrões dos países capitalistas desenvolvidos. Isto implicou na expulsão da população pobre e negra do espaço da "cidade formal", cujo marco foi a derrubada generalizada dos cortiços. Construídos 


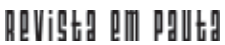

\} CULTURA E TRABALHO - MURAD, L. C. \}

DOI: $10.12957 /$ REP.2016.27856

a partir das necessidades das classes populares de morar perto das áreas centrais, onde se concentravam os empregos relacionados à prestação de serviços (minimamente acessíveis aos ex-escravos), os cortiços já eram perseguidos e estigmatizados desde 1893 pela administração do prefeito Barata Ribeiro, momento no qual se inicia

um processo de intervenção direta do Estado sobre a área central da cidade, que viria a se intensificar sobremaneira a partir do início do século, e que seria responsável pelo aumento da estratificação social do espaço carioca. (ABREU, 2013, p. 50).

Até o início do século XX, o Centro do Rio e suas imediações concentravam também a incipiente atividade industrial, caracterizada pelo "baixíssimo nível de mecanização" e pela existência de indústrias consequentemente capazes de absorver grande quantidade de força de trabalho (ABREU, 2013, p. 54-55). Porém,

O final do século XIX não se caracterizou apenas pela multiplicação de fábricas no Rio de Janeiro. Outra face da mesma moeda, coincidiu também com o esgotamento do sistema escravista, com o consequente declínio da atividade cafeeira na Província do Rio de Janeiro e com o grande afluxo de imigrantes estrangeiros. Resultou daí um processo de crescimento acelerado via migração, que agravou consideravelmente o problema habitacional da cidade, pois levou ao adensamento ainda maior dos cortiços e ao recrudescimento das epidemias de febre amarela que assolavam a cidade periodicamente. (ABREU, 2013, p. 57).

O discurso higienista ganha força no início do século XX, configurando inclusive uma forma de pressão social que se fortalece com a intervenção direta do Estado no âmbito da reprodução da força de trabalho, levada às últimas consequências na administração de Pereira Passos. No caso da urbanização incipiente do Rio de Janeiro, a necessidade de disciplinar a força de trabalho aparece também pautada no discurso higienista na parceria do Estado com as empresas privadas no subsídio da reprodução da força de trabalho, por meio da construção de vilas operárias, projetadas como "moradas hygienicas" ainda na última década do século XIX (ABREU, 2013). Estas, porém, logo se mostraram insuficientes perante a quantidade de pessoas expulsas da área central.

Nesse contexto contraditório de formação do urbano, a vinda de ex-escravos e migrantes pobres (unidos sob a denominação de trabalho livre) para os novos centros urbanos era necessária ao desenvolvimento do capitalismo. Ao mesmo tempo, era combatida por um projeto político e estético de branqueamento, o qual legitima a mudança na inserção do país na divisão internacional do trabalho a partir de alguns determinantes: a necessidade sentida pela elite de que nos assemelhássemos aos países 
centrais, especificamente à estética moderna representada nos grandes centros urbanos; a necessidade do capital de substituição do trabalho escravo por uma mão de obra considerada mais adequada, o que implica no estímulo à imigração a partir da criação de um ideal de colono (SEYFERTH, 2002); e a resistência dos ex-escravos a se adequar ao éthos do trabalho assalariado.

A massa de ex-escravos estava demasiado mutilada para adequarse ao assalariamento. Logo, a transformação destes em trabalhadores "livres" não ocorreu sem resistência por parte dos mesmos. Queiróz (2001) destaca a própria violência, sistematicamente utilizada no cativeiro, como fator que implicava no extermínio da vitalidade do escravo em prazo determinado. Porém, a resistência, quando configurada em reapropriação do tempo pelo ex- escravo, é frequentemente lida como ode à vadiagem, no sentido pejorativo, ou dificuldade moral de integração à nova ordem.

Nesse sentido, o disciplinamento dos corpos, necessário à consolidação da modernidade, ocorre no Brasil como tensionamento contínuo em um movimento de expropriação, inclusive do tempo livre e do espaço, permanência de formas de violência extraeconômica e resistência. É nesse cenário que a vinda de trabalhadores europeus continua a ser estimulada pelo Estado brasileiro, ratificando a política do branqueamento reverenciada pelas elites (MENEZES, 2013). Além disso, é essa política que legitima a expulsão dessa massa de trabalhadores pobres e negros dos grandes centros urbanos no processo de modernização do país, ao mesmo tempo em que esses eram necessários para a realização de determinados trabalhos. O acesso desses segmentos populacionais ao território se faz então por meio da produção de cultura como possível forma de representação das dores individuais/coletivas (BOSI, 2008). A produção de cultura popular implica ainda na ressignificação do território ${ }^{2}$ pela apropriação do espaço da rua, conforme veremos adiante.

A política do branqueamento no Rio de Janeiro é também indicada por Lopes (2008) a partir da análise da composição da força de trabalho realizada por Chalhoub:

em 1890, dos 89 mil trabalhadores estrangeiros em atividade na terra carioca, mais da metade tinha os empregos mais bem remunerados, no comércio, na indústria e nas atividades artísticas; enquanto, entre os negros, $48 \%$ eram empregados domésticos, 17\% eram operários, 16\% não tinham profissão declarada e 17\% trabalhavam em atividades extrativas, na lavoura e na pecuária. E é essa mesma ideologia do branqueamento que vai delimitar o espaço físico a ser ocupado por esses negros, vindos de todo o território brasileiro, na geografia carioca. (LOPES, 2008, p. 40).

${ }^{2}$ Construído e redimensionado no âmbito da expansão das relações mercantis. Espaço da acumulação capitalista. 


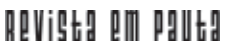

\} CULTURA E TRABALHO - MURAD, L. C. \}

DOI: $10.12957 /$ REP.2016.27856

Logo, as condições de incorporação do negro ao mercado de trabalho nascente são desiguais desde a época da abolição, sendo este um dos determinantes para observarmos o processo de integração do negro na ordem competitiva.

É no movimento de deslocamento forçado, remoção e construção do sistema de transportes (ABREU, 2013) que se constitui o subúrbio carioca, sendo sua origem também marcada pela segregação étnica fundamentada na ideologia do branqueamento. A necessidade de acessar os locais de trabalho, a expulsão continuada do centro da cidade e o desenvolvimento do sistema de transportes para atender às necessidades de reprodução do capital nacional e internacional provocaram um rápido crescimento das áreas em torno dos trens.

A partir da inauguração do primeiro trecho da Estrada de Ferro Dom Pedro II, em 1858, e subsequentes estações e novas ferrovias, o subúrbio carioca começa a se expandir. Na última década do século XIX, início do XX, o Rio de Janeiro já experimentava uma industrialização incipiente. Desse modo, o movimento de ocupação e o crescimento dos subúrbios podem ser exemplificados "pela movimentação de passageiros nas estações da Central do Brasil, que atingiu, no período 1886-1896, um total de quase 30 milhões de pessoas" (ABREU, 2013, p. 53).

Com a Reforma Pereira Passos, a derrubada dos cortiços e a campanha para erradicação dos mesmos se combinaram a desapropriações e demolições em função da renovação do Centro. As favelas se constituíram como parte desse mesmo processo, alternativa aos mais pobres que precisavam continuar perto do Centro perante a expulsão do núcleo central, mas "nem todos os que eram expulsos dos cortiços ou que chegavam à cidade, localizaram-se, entretanto, nas favelas. A grande maioria, ao que parece, instalou-se nos subúrbios, contribuindo assim para a sua ocupação efetiva" (ABREU, 2013, p. 66). Dentre a população de baixa renda expulsa da área central, os negros eram maioria, atingidos inclusive pela mecanização do Porto a partir de 1906 (LOPES, 2008).

O subúrbio carioca foi então construído não como parte de um processo de planejamento urbano, sendo antes resultado de uma ocupação forçada devido ao processo de expulsão sistemática das áreas centrais, iniciado já no final do século XIX. Além disso, foi viabilizado pelo desenvolvimento dos trens no movimento de conferir respostas às necessidades de reprodução do capital. Portanto, com o avanço das linhas férreas e o decorrer do processo de modernização, o trabalhador negro passou a encontrar no subúrbio um local razoável para moradia. Durante esse deslocamento rotineiro casa-trabalho, trabalho-casa, produzia-se também uma sociabilidade original das classes populares:

a inauguração e extensão das linhas da Estrada de Ferro Central do Brasil, por etapas, até o matadouro de Santa Cruz, na segunda metade 
do século XIX, bem como da Avenida Automóvel Clube em 1926; mais a crise do capitalismo mundial em 1929 que, estimulando a indústria nacional, motiva a vinda para o Rio de Janeiro de enormes contingentes da população interiorana; tudo isso vai determinar o crescimento dos morros e dos subúrbios e acabar de definir geograficamente o universo do samba e do partido-alto. (LOPES, 2008, p. 44).

Podemos observar, nesse sentido, a origem de atos, tais quais o samba no trem, como exemplo dessa relação trabalho/cultura popular/ constituição do território. $\mathrm{O}$ ato de fazer samba no trem é uma prática antiga no Rio de Janeiro, surgida de maneira espontânea como reação, no contexto de perseguição e repressão às tradições de matriz afro-brasileiras, principalmente ao samba e ao candomblé (forma religiosa e de sociabilidade vinculada umbilicalmente às origens do samba urbano); o trem seria, neste momento, um espaço livre da repressão policial, onde podia-se fazer o batuque nas horas gastas a caminho de casa e do trabalho.

Conforme indica Lopes (2008), a forma de samba partido-alto também é criada nessa relação, na virada do século XIX para o XX, quando ainda havia grande concentração de negros e mestiços (a maioria oriunda da Bahia e de Minas Gerais) na Zona Portuária e em seus arredores principalmente na Cidade Nova, até então Praça Onze. Essa região, conhecida como Pequena África, é apontada pelo autor como berço do samba urbano, pois ali "confraternizavam-se ou confrontavam-se, nas rodas de batucada e de pernada, os sambistas descidos dos morros e subúrbios" (LOPES, 2008, p. 46).

Ou seja, nesse momento a rua ainda é o espaço da confraternização, e esta ocorre por meio do encontro; nesse movimento, descrito em detalhes e em suas contradições por Lins (2012), observamos a conformação da cultura nos marcos da recriação das tradições africanas, amalgamadas a formas da cultura europeia, paralela à universalização do trabalho assalariado como forma de organização da vida social e à consequente repressão policial, característica do processo por meio do qual a cidade "civilizava-se".

\section{Trabalho e instrumentalização da cultura}

O trabalho alienado se generaliza e se torna laço social central na cultura, consolidando a cisão que funda a modernidade. A dissociação da vida em esferas é representativa desse processo, que resvala também no âmbito da criminalização da cultura popular. Com a modernização do país, a homogeneização das relações sociais vai-se estabelecendo por meio da instrumentalização da cultura. O corpo do trabalhador, nesse sentido, "pode ser interpretado, também, como uma grande metáfora da perversão instituída pelo capitalismo, a partir da instrumentalização da natureza e da humanidade, melhor dizendo, da cultura" (FONTENELLE, 2002, p. 282). 


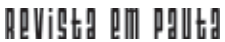

\} CULTURA E TRABALHO - MURAD, L. C. \}

DOI: $10.12957 /$ REP.2016.27856

Ou seja, quando toda atividade humana é transformada em trabalho alienado, no sentido da produção do valor, também os homens em sua corporalidade se transformam em meio na busca incessante de fins alheios, precisando, para isso, serem disciplinados. Nas palavras de Marx (2011, p. 286 - grifos no original), a força de trabalho em sua potencialidade particular de conservar e criar valor "devém força do capital". Logo, o capital só é produtivo em relações de produção, e o trabalho alienado só tem existência nessa relação.

Nessa forma social, os indivíduos criam laços uns com os outros e com a natureza, por intermédio da troca de mercadorias, tendo como finalidade a geração de mais valor. Quer dizer, os sujeitos se tornam objetos no processo produtivo sob o qual eles não exercem nenhum controle, e sua atividade é reduzida a trabalho abstrato. Na produção de mercadorias, o conteúdo concreto que particulariza a atividade humana se apaga ao tornar-se simples invólucro de valor, logo, universal e vendável. Os homens se colocam então em relação com a natureza e com outros homens por intermédio da mercadoria e da criação da forma valor, que dirige o processo produtivo. A finalidade da produção, longe de ser a realização das necessidades humanas, reduz-se grotescamente às necessidades de valorização do valor, o que configura a imposição de uma forma de dominação impessoal perante a criação de um poder autônomo: o capital.

$\mathrm{Na}$ sociedade moderna, os homens entram em relações de troca uns com os outros, de compra e venda, a partir das necessidades de reprodução do capital; isso é estruturante da sociabilidade, pois os sujeitos não determinam a finalidade do processo de produção, mas esta é colocada a priori. Ou seja, não surge da experiência, sendo antes uma marca desta forma social inconsciente. A forma valor enquanto "determinação lógica, está dada anteriormente à experiência" (MENEGAT, 2011, p. 6).

Nesse sentido, os sujeitos se tornam meros operadores da lógica irracional do valor ao irem ao mercado produzir e trocar coisas que não podem "trocar-se por si só", e das quais não necessariamente precisam para responder às necessidades humanas. Muitas dessas coisas estão inclusive em contradição com as necessidades humanas pelo seu poder destrutivo, como é o caso dos alimentos produzidos com agrotóxicos. Estes têm suas propriedades concretas embotadas ao serem reduzidos a mercadorias com alto poder competitivo pela diminuição de tempo de produção. O homem é retirado da condição de finalidade do processo social, tornando-se meio para a reprodução inconsciente da lógica do mesmo.

Logo, a cultura se produz na civilização burguesa como segunda natureza, já que é regida pela lei do valor e se baseia, portanto, em laços sociais abstratos e potencialmente destrutivos. A lei do valor suscita a naturalização da objetividade alienada e, consequentemente, o empobrecimento da experiência (BENJAMIN, 1994) e da subjetividade, já que os homens não autodeterminam suas atividades. 
O domínio impessoal do capital representa então a subjugação dos homens e sua entrega contínua ao processo automático de transformação de trabalho em dinheiro, por meio da coação econômica. Na sociedade fetichista, o sujeito que determina o processo social, sendo inclusive finalidade do mesmo, é o capital em suas várias formas: o valor, a mercadoria, ou seja, as formas pelas quais os homens objetivam suas relações sociais. Uma vez que o trabalho alienado constitui-se em um meio para o fim da valorização do valor, as relações sociais são organizadas a partir do controle do tempo dos indivíduos.

Sendo o processo de valorização uma forma produtiva abstrata, mensurada pelo tempo, podemos concluir que o processo de formação subjetiva da classe trabalhadora ocorre na determinação da formação objetiva de uma massa de trabalhadores, unificada pela instrumentalização do corpo e pelo caráter abstrato do sistema.

O último ponto para o qual é preciso chamar a atenção no trabalho, tal como ele se defronta com o capital, é que o trabalho, como $o$ valor de uso que se defronta com o dinheiro posto como capital, não é esse ou aquele trabalho, mas é trabalho por excelência, trabalho abstrato: absolutamente indiferente diante de sua determinabilidade particular, mas suscetível de qualquer determinação. À substância particular que constitui um capital determinado tem naturalmente de corresponder o trabalho como trabalho particular; no entanto, como o capital enquanto tal é indiferente perante a qualquer particularidade de sua substância, e é tanto a totalidade da substância quanto a abstração de todas as suas particularidades, o trabalho que o defronta possui em si subjetivamente a mesma totalidade e abstração. (MARX, 2011, p. 230 - grifos no original).

Por isso o corpo expressa essa inversão pela qual o capitalismo se constitui como forma sistêmica, na qual a forma mercadoria (consequentemente, as relações baseadas no valor de troca) se torna a forma das relações estabelecidas entre os homens.

O trabalho não é somente o valor de uso que se defronta com o capital, mas é o valor de uso do próprio capital. Como o não ser dos valores como valores objetivados, o trabalho é seu ser como valores não objetivados, seu ser ideal; é a possibilidade dos valores e, como atividade, o pôr de valor. Diante do capital, o trabalho é a simples forma abstrata, a simples possibilidade de atividade que põe valor, que só existe como habilidade, faculdade, na corporalidade do trabalhador. [...]. Por um lado, a objetividade de que consiste o capital tem de ser elaborada, i.e., consumida pelo trabalho, por outro, a simples subjetividade do trabalho como mera forma tem de ser abolida e objetivada no material do capital. (MARX, 2011, p. 231; p. 232 - grifos no original).

O capitalismo, em seu processo de consolidação histórica, inverte a lógica posta no processo de produção simples, o que implica em uma 


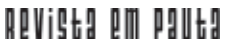

\} CULTURA E TRABALHO - MURAD, L. C. \}

DOI: $10.12957 /$ REP.2016.27856

unidade dialética na qual trabalho é força do capital. Em decorrência, ocorre a separação das esferas de vida do homem. O ser humano, em sua condição de trabalhador, está pressuposto no processo de valorização do valor, ou seja, a realização das necessidades humanas não é a finalidade da produção, sendo o homem forçado a embarcar no processo inconsciente de valorização do valor para sobreviver. Somente no processo produtivo o homem moderno se reencontra com as condições de reprodução de sua existência racionalizada:

No processo de produção, a separação do trabalhador de seus momentos de existência objetivos - instrumento e material - é superada. Sobre a separação repousa a existência do capital e do trabalho assalariado. [...] O processo de valorização do capital tem lugar pelo e no processo de produção simples, pelo fato de que o trabalho vivo é posto em sua relação natural com seus momentos de existência material. Contudo, à medida que o trabalho entra nessa relação, a relação já não existe para ele mesmo; ela própria já é um momento do capital. (MARX, 2011, p. 290; p. 291 - grifos no original).

A cisão constitutiva da modernidade aparece então na separação entre a produção da existência, antes determinante na produção de cultura - que passa a ser determinada no âmbito da produção e reprodução do valor por meio do trabalho alienado -, no tempo livre do trabalhador e no domínio das esferas da vida social pela determinação econômica. Nesse sentido, a cultura vai-se homogeneizando no movimento mesmo de expansão mundial do capital, o qual suprime a parte e inviabiliza qualquer forma particular de cultura, de vida comunitária não determinada pela sociabilidade da mercadoria - ao mesmo tempo em que as torna cada vez mais necessárias. Quando a cultura se torna parte constitutiva do capital, enquanto um universal abstrato, o não idêntico é suprimido pela sua integração ao todo. Conforme Scholz (2014) indica, aquele que não é integrado pelo trabalho passa a ocupar um não lugar, atribuído nos marcos da mistificação da cultura.

Assim, o capital é a intencionalidade que move o processo social, colonizando os espaços pela imposição da lógica da mercadoria como universal abstrato. Sendo assim, a ausência de sujeitos que possam autodeterminar a produção da vida social e conferir a esta outro conteúdo, mais sintonizado com as necessidades humanas, coloca um problema para a produção de cultura. Dessa forma, ela é eclipsada enquanto possibilidade de criação humana e expressão particularizada da relação homem-homem e homem-natureza. Nesses moldes, a cultura só pode se reafirmar como "cultura da destruição" (MENEGAT, 2003).

O valor como intencionalidade do processo social estabelece uma forma de dominação impessoal, na qual a cultura é um apêndice, uma das esferas da vida separada das demais. A naturalização de tal separação já é, 
porém, parte do processo de degradação da cultura. A mesma só pode ser entendida nessa chave como uma espécie de superestrutura - quando a civilização vai-se impondo como segunda natureza regida pelo mecanismo cego de reprodução do valor, alienada.

As sociedades antigas não viviam sob essa cisão, pois nelas a experiência se dava no âmbito de uma existência integrada, constituinte daquelas culturas, as quais não estavam determinadas pelas necessidades de reprodução do valor. Nesse sentido, a produção direta da vida determinava a organização do tempo, das relações sociais e a própria ligação entre os homens, sendo as relações intergeracionais e o conhecimento sensível acerca da natureza fundamentais nesse processo.

O domínio do capital - este mesmo uma relação social que pressupõe o trabalho alienado, como observou Marx - representa a inviabilidade de qualquer cultura autodeterminada, dada sua necessidade de colonizar o tempo e todos os espaços da vida social em função do movimento tautológico de valorização do valor. A própria noção de progresso, instaurada durante a colonização, é em si uma forma de positivação do domínio do homem branco, que permite coisificar povos e culturas diferentes em um processo que envolve a infantilização do outro e a bestialização de si mesmo. O ódio racial, o racismo e as formas similares de discriminação têm lugar nesse movimento.

Sendo o capital uma "forma total de reprodução social", o que se tornou a cultura? De acordo com Hardman (1984), a cultura tende a reproduzir a forma de dominação específica, característica da sociedade moderna; porém, cabe notar o caráter contraditório desse processo:

essa cultura, numa análise mais atenta, poderia revelar, nos interstícios de seus discursos, a presença subterrânea e efetiva de aspirações e concepções próprias da forma de existência social e da posição relativamente diferenciada das classes trabalhadoras. (HARDMÁN, 1984, p. 112).

Na pista de Raymond Williams $(1979 ; 1992 ; 2007)$, o autor indica a relevância de se observar espaços de festa e lazer, de celebração da classe trabalhadora, no sentido de entender a constituição particular da mesma em seu contraditório processo de formação, observando também essa experiência enquanto constitutiva dos grandes centros urbanos. Os espaços de lazer da classe trabalhadora e sua produção descompromissada fundamentam também a leitura de Rancière (1988). O autor analisa obras dos proletários (jornais, poemas, pequenas publicações) da França no período de revoluções e levantes, entre 1830 e 1898. Observa as perspectivas dominantes entre eles e suas contradições, buscando um quadro geral da construção da identidade operária nesse contexto, em particular nas noites onde estes produzem conhecimento ao se subtrair da rotina de trabalho. 


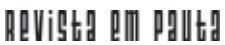

\} CULTURA E TRABALHO - MURAD, L. C. \}

DOI: $10.12957 /$ REP.2016.27856

A embriaguez do lazer rompe a rotina do descanso requerido como parte do processo de trabalho alienado. Pode expressar a ruptura de hierarquias, principalmente da hierarquia entre os que trabalham e os que pensam, porém, em uma dialética na qual opressão e resistência às vezes se confundem. Essa dialética aparece na criação de uma imagem e de um discurso identitário operário. A ruptura de hierarquias, a insurreição momentânea que remete aos antigos carnavais é "necessária para reproduzir o equilíbrio entre dominantes e dominados" (RANCIÈRE, 1988, p. 37).

Uma espécie de racionalidade antimercadoria se expressa em algumas obras escritas dos proletários, como desejo de poder escolher sua ocupação. Na forma social moderna há a imposição da separação entre a vocação de cada ser e sua condição, necessariamente de alienação, bem como da separação entre os que pensam e os que trabalham com as mãos. Ao se defrontar com o outro e seus luxos, o proletário se depara com suas privações, podendo adquirir, assim, novas paixões que colocam em questão a divisão social do trabalho e revelam a cruel exploração e o roubo de seu tempo de vida. Contudo, para além disso, também revelam outro ser possível.

Tendo isso em vista, o autor reafirma a experiência dos "de baixo" como fundamental no sentido de conhecimento de si e das formas de dominação, entendendo o proletário como um ser na fronteira, visto que as vias que conduzem à dominação se confundem com a simples existência proletária.

Na formação do Brasil, a cultura popular e o samba urbano, constitutivo da formação de uma cultura negra no Rio, oferecem pistas quanto à vivência das classes subalternizadas em condições de acumulação primitiva e suas formas de resistência. Afinal, até cerca da metade do século $\mathrm{XX}$, no país, os momentos de tempo livre e de lazer das massas ainda não estavam atrelados por completo ao processo de valorização do valor, considerando o caráter tardio de nossa modernização.

A separação completa da vida em esferas cindidas no contexto nacional estava associada ao fim da escravidão, porém, isso também significou a apropriação de determinado tempo e espaço pelos "novos trabalhadores livres". Nos espaços de deslocamento e de descanso, a reapropriação do corpo se impunha como forma de sociabilidade, por meio da produção de cultura popular e da criação de espaços de lazer e de festa não mercantis, onde ocorria o encontro.

\section{Entre a resistência e a modernização: o samba urbano e a integração do negro}

A produção de cultura pelas classes populares, nesse momento de constituição do subúrbio carioca, no bojo do processo de modernização do país, ainda destoa da instrumentalização da cultura operada pela lógica 
do capital. Paradoxalmente, o disciplinamento para o trabalho também coloca a necessidade de um lugar para o lazer. Uma espécie de caldo de cultura criminalizado nas ruas como vadiagem, no contexto onde os momentos de lazer das classes pobres eram tidos como espaços improdutivos, violentos e perigosos, encontrava espaço fértil para se desenvolver nos morros e no subúrbio carioca. O samba urbano nasce como expressão dessa sociabilidade, ganhando contornos bem definidos com o desenvolvimento dos blocos carnavalescos suburbanos - com destaque aos nascidos nos bairros Estácio, Mangueira, São Carlos e Osvaldo Cruz -, em uma prática de criação de composições anônimas coletivizadas, que tem na figura do malandro sua forma de representação mais expressiva.

Matos (1982), a partir da análise do samba carioca que teve como motivo central a malandragem, indica que, no Rio de Janeiro da primeira metade do século $X X$, o malandro era sujeito e objeto do samba urbano. $O$ texto malandro (o samba urbano) das décadas de 1930, 1940 e 1950 representa poeticamente as contradições oriundas do desenvolvimento urbano, particularmente a tensão entre as formas de sociabilidade popular que originaram o samba urbano em sua originalidade e a instituição do culto ao trabalho pelo Estado Novo (1937) - culminando no aparecimento, na década de 1940, do "malandro regenerado" e no descenso do tema da malandragem no samba pós-década de 1950.

As contradições apontadas pela autora aparecem, porém, não como constitutivas de uma forma estética de criação individual, sendo antes inerentes à

produção de um grupo social que, embora heterogêneo, está ligado por determinados fatores sociais, étnicos, econômicos, culturais. Essa tendência para uma forma de autoria que transcende os limites da individualidade, dando voz a um ser coletivo, está na raiz da produção do samba e de nossa música negra em geral. (MATOS, 1982, p. 19).

Como gênero musical, o samba urbano carioca passa a ser reconhecido como constituinte da cultura nacional a partir do final da década de 1930. Nesse cenário, o trabalho alienado se generaliza como laço social abstrato, e o Estado Novo recoloca o samba como instrumento no disciplinamento dos corpos - no contexto de substituição dos trabalhadores imigrantes pelos nacionais. Com a indústria radiofônica (a partir de 1932) e seu fortalecimento, o reconhecimento do samba vem paralelo à sua comercialização e à profissionalização do músico negro, sendo a autoria individual uma imposição crescente nesses marcos. A prática de compor coletivamente perde seu lugar, conforme a transformação do samba em mercadoria.

Contudo, o reconhecimento e a posterior aceitação do samba como expressão típica da cultura popular nacional (mesmo que já fora de seu contexto) não necessariamente retiraram o negro e o pobre de seu não lugar destinado no processo de acumulação primitiva no Brasil. As repre- 


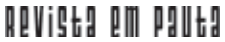

\} CULTURA E TRABALHO - MURAD, L. C. \}

DOI: $10.12957 /$ REP.2016.27856

sentações sociais acerca das favelas e áreas periféricas como lugares perigosos, sujos e violentos persistiram no imaginário coletivo, tendo raízes principalmente na redução do homem a um animal e pela transformação do mesmo em instrumento de trabalho, como observa Candido (2002) ao analisar a obra $O$ cortiço e as relações que fundamentam as representações nela contidas. Estas representações legitimam a criminalização do samba urbano quando associado a uma condição marginal.

A cultura popular expressa no samba urbano aponta também, nesse sentido de sua criminalização, para uma forma de integração perversa da população negra, integração tão frágil quanto o discurso segundo o qual não existe racismo no Brasil. Para ser reconhecido como constitutivo da cultura nacional, o samba urbano - nascido e desenvolvido a partir da transformação de tradições africanas - passou por um processo de dissociação da sociabilidade que o originou em sua forma popular. Persistiu, porém, a necessidade de espaços de lazer e de encontro entre as classes populares, mesmo com o esvaziamento das ruas e dos espaços públicos, ainda no contexto da política disciplinar para o trabalho e criminalização da "vadiagem".

Cabe notar que a ocupação dos espaços públicos por festivais populares foi significativa na história da luta de classes no Brasil no início do século XX. Hardman (1984) aponta esse movimento:

Com efeito, a tradicional festa de propaganda realizada em salões das ligas e entidades de classe foi substituída por festivais, piqueniques e excursões a lugares públicos, ao ar livre, patrocinados pelos jornais da imprensa operária. [...] Em 1917, junto com o aparecimento de $A$ Plebe, começam a surgir os primeiros anúncios de 'festivais públicos', que se estenderão inclusive pelos anos 20-30. No Rio de Janeiro, a mesma tendência se verifica, por exemplo, no jornal Voz do Povo. [...] a novidade dessa fase é o festival-espetáculo que converte a festa de propaganda (onde o aspecto doutrinário e educativo ressaltava mais) em uma aparatosa gama de diversões populares e massivas, onde o aspecto lúdico de entretenimento coletivo é o principal. (HARDMAN, 1984, p. 38; p. 39).

O autor observa aqui outra concepção de festivais, entendidos como um momento lúdico da práxis, portanto essencialmente político. O processo de ocupação dos espaços públicos, fundamental para o ato de fazer política, ocorreu nesse momento mediado pelo lazer e pela necessidade de encontro fora do espaço do trabalho. Não por acaso, o domingo era representativo como "único momento oficializado pelo Estado e abençoado pela Igreja como 'tempo livre', curto intervalo em que o operário sai do laboratório de extração da mais-valia e se localiza no território da cidade" (HARDMAN, 1984, p. 14). Potencialmente carregava a recusa do confinamento territorial consequente da criação dos bairros proletários. 
Parece não haver dúvida de que o processo de conquista dos espaços públicos e ao ar livre por este tipo de acontecimento foi um longo capítulo no processo de luta de classes e de posição de força do movimento operário. A época da explosão dos festivais proletários (a partir de 1917) é a época do grande ascenso mobilizatório do movimento operário. (HARDMAN, 1984, p. 42).

Observando a construção do urbano no Rio de Janeiro, no entanto, é perceptível a existência de um elemento étnico que divide a classe trabalhadora. É pela ocupação das ruas como lócus privilegiado de sociabilidade que os negros reconstroem tradições fora do espaço institucional das lutas de classes e do trabalho. Fernandes (2008) indica o elemento étnico como determinante a partir da análise do pauperismo urbano na realidade de São Paulo. O autor constata a exclusão dos negros das tendências modernas do capitalismo em expansão, exclusão que se expressa em uma forma de segregação difusa ou, conforme Menezes (2013), em uma forma de racismo transversal ${ }^{3}$.

Trocando em miúdos, apesar de não haver no Brasil um sistema de segregação racial instituído por lei, a cor da pele é determinante nas relações sociais, e o racismo contribui para as formas de dominação instituídas e para o modelo de exploração capitalista vigente no país (MENEZES, 2013). Logo, sendo a experiência marcada pela cor da pele, não é possível pensarmos em formas identitárias constituídas somente pelo lugar ocupado pelos indivíduos no sistema de classes. O racismo como determinante influencia inclusive nas formas diversas de vivência do movimento operário então em ascensão, sendo estruturante tanto da ordem competitiva quanto da subjetividade dos trabalhadores negros.

No Rio de Janeiro em construção, mesmo com a proletarização dos negros, trabalhadores principalmente da estiva no Porto, a cor da pele aparece como determinante, por exemplo, nas situações em que os negros eram abordados pela polícia e se identificavam como estivadores para fugir da "dura", sendo levados para serem confrontados por um sócio da União e apresentar seu recibo do mês para comprovar a condição de trabalhador (BUENO, 2002). Não por acaso, foi criada a Companhia dos Pretos (Sociedade de Resistência dos Trabalhadores em Trapiches de Café).

Ou seja, aos negros foram delegados os postos mais baixos no incipiente mercado de trabalho, além de estarem sujeitos a todo tipo de constrangimento pelo simples ato de vagar pelas ruas. Segundo Lins (2012), alguns negros, ao se desligarem do trabalho, mantinham consigo a comprovação para escapar da "dura" da polícia. A partir disso, percebemos que a segregação étnico-racial difusa determina tanto o lugar diferenciado

\footnotetext{
${ }^{3}$ Conceitos que particularizam a forma de racismo que se desenvolveu no Brasil, a qual não está baseada na segregação instituída por lei, nem na separação de territórios específicos para negros. Está presente, porém, no cotidiano, sendo assim difusa, pois consolidada nas práticas sociais inter-raciais.
} 
do negro no espaço da exploração capitalista quanto na conformação da classe operária no Brasil.

Menezes (2013) lembra que, apesar de a passagem do período colonial para o processo de industrialização nacional ter sido financiada com a acumulação resultante do trabalho compulsório do negro, tanto a lei de terras quanto a política do branqueamento resultaram na estratificação racial durante a conformação do trabalho livre e, consequentemente, na marginalização dos negros após a abolição:

De forma irônica e controversa - bem à moda capitalista, estavam lançadas as bases que constituem, ainda hoje, a maioria do contingente de inimpregáveis, subempregados e superexplorados, que formam hoje a base da pirâmide social brasileira. (MENEZES, 2013, p. 25).

Fernandes (2008) observa a condição dos negros nas primeiras décadas do século XX em São Paulo e nota que, em regra, eram raros os que não exerciam ocupações braçais e que possuíam profissão definida. Com a subdivisão e maior especialização do trabalho nos marcos da sociedade industrial, a condição dos negros recém-saídos da escravidão se agravou perante a incerteza e a ausência de perspectivas.

A partir das condições dos negros em São Paulo nas três primeiras décadas do século XX apresentada por Fernandes (2008), nota-se que a complexificação da divisão do trabalho própria do desenvolvimento do sistema capitalista consolidou a separação trabalho-cultura e inviabilizou formas comunitárias de produção da vida social, representando para os negros uma forma de desconstrução de suas formas culturais. Porém, estas foram desconstruídas sem que eles fossem necessariamente integrados na civilização nascente.

Estabeleceu-se um verdadeiro e insuperável círculo vicioso entre a herança sociocultural, transplantada da senzala e do antigo regime, e a exclusão permanente do negro e do mulato das formas de 'ganhar a vida', nascidas da revolução urbana e industrial. Na medida em que podia ser identificado por aquela herança, o 'negro' se via barrado daquelas formas de ganhar a vida; e, na medida em que isso acontecia, ele não tinha nenhuma possibilidade real de absorção gradativa pela civilização urbana e industrial. (FERNANDES, 2008, p. 172).

O desemprego e a substituição dos negros, além da expropriação contínua da terra, conformaram assim o padrão de organização do trabalho livre na sociedade brasileira.

Poucos conseguiram se classificar como 'operários', seja porque se temia a sua falta de preparo técnico, seja porque se valorizava preferencialmente o 'trabalhador estrangeiro', seja enfim porque os pró- 
prios 'negros' e 'mulatos' se retraíam, candidatando-se de preferência às oportunidades de trabalho que lhes eram mais acessíveis. (FERNANDES, 2008, p. 163).

Isso condenou os negros a uma espécie de isolamento disfarçado no processo de ajustamento ao mundo urbano, conforme indica o autor. Fernandes (2008) aponta ainda a privação do convívio como uma consequência determinante para o uso da rua como espaço de congregação.

Cabe notar que, apesar de a leitura de Fernandes (2008), indicadora da condição dos negros na ordem competitiva, representar um avanço com relação a leituras anteriores, nas quais a chave analítica determinante era o biológico, o autor tende a positivar o papel e a função das instituições modernas, inclusive da própria família. Logo, embora ele indique o aniquilamento do negro em suas várias formas como uma constante na sociedade competitiva, sendo característica do racismo e da segregação difusa, Fernandes (2008) denuncia a democracia racial como mito, projetando-a enquanto horizonte a ser alcançado, adiado devido à incompletude da modernização.

De acordo com Paixão (2014), Fernandes ocupa lugar de destaque no pensamento social brasileiro acerca das relações raciais. Porém, sua leitura limita-se aos marcos do culturalismo, visto que nessa perspectiva se expressa certo padrão compensatório. Neste padrão, é reconhecida a existência das desigualdades raciais, as quais seriam compensadas pela forma não segregacionista (em comparação com os EUA) de relações raciais. A modernização incompleta é então positivada no sentido do não desencantamento do mundo, da permanência da forma pessoal de se relacionar; nessa forma mista e incompleta residiria o racismo. Assim, conforme a evolução da ordem competitiva, o processo de integração do negro na sociedade de classes aconteceria, ou melhor, estaria completo. Esta seria então a consequência não intencional implícita no pensamento do autor (PAIXÃO, 2014).

Na leitura que esboçamos, o racismo e as desigualdades raciais "se aprofundam em cada novo ciclo de modernização da nação" (PAIXÃO, 2014, p. 353). Logo,

não consideramos que as assimetrias nas condições de vida entre brancos e negros formem uma espécie de subproduto indesejado de interações supostamente virtuosas no plano das relações intersubjetivas. Antes, as diferenças nas condições de vida entre brancos e negros são elementos essenciais de todo o modelo. (PAIX ̃̃O, 2014, p. 352).

Afinal, se a interação inter-racial ocorre de maneira diferenciada no Brasil no plano intersubjetivo, os tensionamentos e as velhas práticas de indicar aos negros "seu lugar" estão igualmente presentes, conforme atestam os próprios relatos contidos na obra de Fernandes (2008 - em particular, 


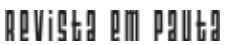

\} CULTURA E TRABALHO - MURAD, L. C. \}

DOI: $10.12957 /$ REP.2016.27856

no cap. 3). A questão é que o racismo e a segregação racial não se propagam somente devido a "reminiscências vivas do passado e estruturas arcaicas que reconstruíram o antigo regime em vários níveis da convivência humana" (FERNANDES, 2008, p. 300), sendo antes constitutivos do próprio processo de modernização - no qual o arcaico é recriado como parte constitutiva da forma moderna.

O peso destrutivo das desvantagens que os ex-agentes do trabalho escravo carregam, sinalizado por Fernandes (2008), é então reatualizado conforme a generalização das relações competitivas ${ }^{4}$, configurando relações de poder e uma forma cultural na qual o negro interioriza paulatinamente uma experiência marcada pela sensação de inferioridade - a qual pode levar ao aniquilamento social que precede o aniquilamento real. Nesse quadro, os negros que alcançam um patamar de classe média configuram a exceção que, enquanto tal, acaba por confirmar a regra.

A atribuição de Fernandes (2008) do racismo e das condições desiguais à permanência de critérios anacrônicos de distribuição de papéis sociais fundamenta também a leitura do autor no que tange à condição de "desajustamento" social dos negros. Nessa perspectiva, a sociabilidade "peculiar" dos negros, assim como certos hábitos mal vistos socialmente, relacionam-se à incapacidade das instituições modernas de integrarem socialmente este segmento populacional. É nesse sentido que a congregação nas ruas aparece na obra do autor como fuga do isolamento. A construção de festas no subúrbio e nos bairros negros no Rio de Janeiro do início do século XX confirma tal conclusão, porém nega suas premissas.

A rua se afirma como espaço de sociabilidade dos negros justamente no processo de construção do urbano e de expansão das relações capitalistas, que teve como consequência, no Rio de Janeiro, a conformação do samba urbano enquanto forma original privilegiada de expressão e criação coletiva, sendo inclusive uma maneira de reapropriação do espaço no contexto de criminalização da vadiagem e generalização do trabalho livre - quando a cultura é necessariamente dissociada das formas de produção da vida.

No Rio, os encontros de samba promovidos principalmente pelos candomblecistas em bairros até então negros - Saúde, Cidade Nova, Riachuelo, Lapa - "constituíam uma das maneiras de as pessoas de cor no Rio de Janeiro reforçarem suas próprias formas de sociabilidade e seus padrões culturais, marginalizados e contudo sobreviventes em séculos de escravatura" (MATOS, 1982, p. 26). Ou seja, o samba urbano é parte da produção cultural das classes populares e envolveu a recriação de tradições negras em um movimento de ressignificação do território.

\footnotetext{
${ }^{4}$ A generalização da ordem competitiva significa a garantia da imposição das leis econômicas no cotidiano das relações sociais (MARX, 2011).
} 
A partir da década de 1950, porém, observamos o refluxo desse movimento de ocupação dos espaços públicos por festas populares. A penetração da indústria cultural no país e sua consolidação após a década de 1970 ressignifica a noção de lazer e divertimento, sendo fundamental no processo de despolitização do ato de celebrar realizado pelos segmentos subalternizados. A necessidade de haver um espaço para reunir-se em momentos de lazer permanece principalmente para os negros, que continuam vivenciando a exclusão de espaços brancos.

\section{Considerações finais}

Conforme a generalização da sociabilidade capitalista e a modernização do país avançam, opera-se então, no espaço urbano, mais especificamente nas ruas, um movimento de esvaziamento, sobretudo após a década de 1970. Isto porque é nesse momento que indústria cultural se consolida no Brasil, promovendo uma integração perversa da produção cultural popular ao sistema pela predominância da forma mercantil. É no bojo dessa contradição que, no subúrbio carioca, multiplicam-se práticas de samba de roda no estilo fundo de quintal, já no movimento de adequação do samba ao gosto da elite carioca.

Já no início do século XX temos notícia de samba fundo de quintal na casa de Tia Ciata, onde foram criados sambas coletivos como Pelo telefone, posteriormente consagrado no cenário da música brasileira. No entanto, nessa época tratava-se literalmente de rodas de samba fundo de quintal, sendo que hoje "fundo de quintal" é uma expressão menos literal quando se trata do turismo cultural e da popularização das rodas de samba.

Na formação da sociedade brasileira, a dificuldade de integração do negro, inclusive relativa ao território e ao lazer - dada a criminalização da sociabilidade constituída nas ruas e visto que ainda em meados da década de 1950 mesmo os negros de classe média eram impedidos de entrar em clubes sociais brancos -, é um paradoxo constitutivo do próprio processo de modernização tardia. A vinda de ex-escravos para as áreas centrais foi uma necessidade no processo de instituição do trabalho livre e, ao mesmo tempo, a reprodução e sobrevivência da população negra tem sido dificultada, quando não inviabilizada, devido às necessidades de reprodução do capital.

No Rio de Janeiro, em particular, quando ocorre algum tipo de integração dos segmentos negros, este é propiciado por intermédio da produção de cultura, mais especificamente, da incorporação do samba urbano como parte da vida cultural do país e seu consequente e paradoxal branqueamento (SILVA, 2008), já nos marcos de constituição da indústria cultural e da monetarização da vida social. 


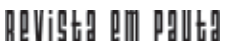

\} CULTURA E TRABALHO - MURAD, L. C. \}

DOI: $10.12957 /$ REP.2016.27856

Completada a modernização, a parcela brasileira dos trabaIhadores em condições precarizadas ainda se constitui em sua maioria de população negra (pretos e pardos) ${ }^{5}$; nesse sentido, o acesso ao lazer e à cultura na época da indústria do entretenimento recria a individualização nos marcos da mercadoria, recolocando uma forma de sociabilidade necessariamente segregacionista, onde são reatualizadas formas de racismo (SCHOLZ, 2014). Sendo assim, a cultura no subúrbio do Rio de Janeiro é representativa da cisão que institui a modernidade nos países periféricos, de modo que a questão da integração do negro é emblemática quanto às formas de exclusão criadas e recriadas no processo de modernização e em condições de crise estrutural do capital.

Se em condições de acumulação primitiva a produção de formas distintas de sociabilidade e de cultura ocorreu como resistência - também no espaço urbano, considerando o subúrbio carioca como um facilitador quanto à cultura negra, que recuperava algo da memória coletiva desse grupo étnico social -, o que se desenha hoje, depois de completada a modernização? Qual a possibilidade de os sujeitos se exercerem como produtores de cultura, quando há a mercantilização da vida? Sendo a cultura sistêmica nessa forma social, podemos ainda tratar a questão nos termos de cultura popular?

Tais questões são fundamentais para esboçarmos uma crítica da cultura, bem como da segregação racial e suas consequências, as quais caracterizam nossa formação social como país de capitalismo periférico, e voltam a nos espreitar em tempos de crise do capital.

Notamos que o próprio processo de modernização institui o racismo enquanto prática social imprescindível no âmbito do desenvolvimento desta forma social inconsciente. Não obstante, o próprio desenvolvimento da ordem competitiva possibilitou a criação de formas de sociabilidade que, até então, representavam uma espécie de alteridade perante a generalização da ética do trabalho necessária à modernização.

Nesse sentido, a construção do território (do Rio de Janeiro enquanto lócus urbano, no caso), a paradoxal produção de uma sociabilidade espontânea que originou o que chamamos de samba urbano e a construção de um não lugar ${ }^{6}$ destinado ao negro na ordem competitiva são determinantes interligados ao observarmos a questão da integração do negro por meio da cultura no Rio de Janeiro.

\footnotetext{
${ }^{5}$ Ver: Menezes (2013) e Ipea (2014).

${ }^{6} \mathrm{O}$ qual pode ser observado ao analisarmos as condições de inserção subalternizada dos negros no mercado de trabalho, bem como a política atual de extermínio da juventude negra, colocada em prática no âmbito da militarização do território.
} 


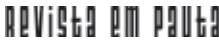

\} CULTURA E TRABALHO - MURAD, L. C. \}

DOI: $10.12957 /$ REP.2016.27856

\section{Referências}

ABREU, M. A. A evolução urbana do Rio de Janeiro. Rio de Janeiro: Iplanrio, 2013.

BENJAMIN, W. Experiência e pobreza. In: BENJAMIN, W. Magia e técnica, arte e política. São Paulo: Brasiliense, 1994.

BOSI, Alfredo. Literatura e resistência. SP: Companhia das Letras, 2008.

BUENO, A. Gamboa: desterro e resistência. Rio de Janeiro: Relume Dumará, 2002.

CANDIDO, A. Duas vezes "Para ir do dois ao três". In: Textos de intervenção. v.1. São Paulo: Duas Cidades/Ed.34. 2002.

CARDOSO, F. H. A cidade e a política. 2006. Disponível em: <http:// www.cebrap.org.br/v2/files/upload/biblioteca_virtual/a_cidade_e_a_ politica.pdf>. Acesso em: 7 abr. 2015.

FERNANDES, F. A integração do negro na sociedade de classes: o legado da raça branca. São Paulo: Globo, 2008.

FONTENELLE, I. A. O nome da marca: McDonald's, fetichismo e cultura descartável. São Paulo: Boitempo, 2002.

HARDMAN, F. F. Nem pátria, nem patrão: vida operária e cultura anarquista no Brasil. São Paulo: Brasiliense, 1984.

IPEA. Situação social da população negra por estado. Brasília: Ipea, 2014.

LINS, P. Desde que o samba é samba. São Paulo: Planeta, 2012.

LOPES, N. Partido-alto: samba de bamba. Rio de Janeiro: Pallas, 2008.

MATOS, C. N. de. Acertei no milhar: malandragem e samba no tempo de Getúlio. Rio de Janeiro: Paz e Terra, 1982.

. Grundrisse: manuscritos econômicos de 1857-1858 - esboços da crítica da economia política. São Paulo: Boitempo; Rio de Janeiro: UFRJ, 2011.

MENEGAT, M. Depois do fim do mundo: a crise da modernidade e a barbárie. Rio de Janeiro: Relume Dumará: Faperj, 2003.

. O giro dos ponteiros do relógio no pulso de um morto. Revista Epos, 2011. Disponível em: <http://revistaepos.org/?p=356>. Acesso em: 12 jun. 2012.

MENEZES, F. C. de. Repensando a funcionalidade do racismo para o capitalismo no Brasil contemporâneo. Revista Libertas, vol. 13, n. 1, 2013. Disponível em: <http://libertas.ufjf.emnuvens.com.br/libertas/article/view/2687/ 1943>. Acesso em: 27 mar. 2015. 
PAIXÃO, M. A lenda da modernidade encantada: por uma crítica ao pensamento social brasileiro sobre relações raciais e projeto de Estado-Nação. Curitiba: CRV, 2014.

QUEIRÓZ, S. R. R de. Escravidão negra em debate. In: FREITAS, M. Historiografia brasileira em perspectiva. São Paulo: Contexto, 2001.

RANCIÈRE, J. A noite dos proletários. São Paulo: Companhia das letras, 1988.

ROSEMBERG, F.; PIZA, E. Analfabetismo, gênero e raça no Brasil. Revista USP, São Paulo, dez./fev., 1995/1996. Disponível em: <http://www.usp.br/ revistausp/28/08-fulvia.pdf>. Acesso em: 10 jan. 2014.

SCHOLZ, R. Homo Sacer e os ciganos: o anticiganismo - reflexões sobre uma variante essencial e por isso esquecida do racismo moderno. Lisboa: Antígona, 2014.

SEYFERTH, G. Colonização, imigração e a questão racial no Brasil. Revista USP, São Paulo, n. 53, mar./maio 2002.

SILVA, F. E. Candeia e a Escola de Samba Quilombo: a crítica ao processo de branqueamento das manifestações culturais afro-brasileiras. Trabalho de Conclusão de Curso (Graduação - Curso de História da Universidade Guarulhos), UnG, Guarulhos, 2008 (mimeo).

WILLIAMS, R. Marxismo e literatura. Rrio de Janeiro: Zahar, 1979. . Cultura. Rio de Janeiro: Paz e Terra, 1992. . Palavras-chave: um vocabulário de cultura e sociedade. São Paulo:

Boitempo, 2007.

Recebido em 22 de julho de 2015.

Aprovado para publicação em 26 de maio de 2016.

DOI: $10.12957 /$ rep.2016.27856

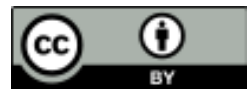

A Revista Em Pauta: Teoria Social e Realidade Contemporânea está licenciada com uma Licença Creative Commons Atribuição 4.0 Internacional. 